TITLE:

\title{
Infrared Studies of Rubber-Filler System. (II) : Identification of Rubbers compounded with Fillers by Infrared Absorption Spectra
}

\section{$\operatorname{AUTHOR}(S):$}

Suito, Eiji; Arakawa, Masafumi

\section{CITATION:}

Suito, Eiji ... [et al]. Infrared Studies of Rubber-Filler System. (II) : Identification of Rubbers compounded with Fillers by Infrared Absorption Spectra. Bulletin of the Institute for Chemical Research, Kyoto University 1963, 40(5-6): 300-306

ISSUE DATE:

1963-01-30

URL:

http://hdl.handle.net/2433/75932

RIGHT: 


\title{
Infrared Studies of Rubber-Filler System. (III)
}

\author{
Identification of Rubbers compounded with \\ Fillers by Infrared Absorption Spectra
}

\author{
Eiji Surto and Masafumi Arakawa* \\ (Suito Laboratory) \\ Received June 27, 1962
}

\begin{abstract}
Infrared spectra of vulcanized rubbers compounded with fillers were studied on the thin sections of samples made by low temperature microtome technique. In this method, identification of fillers compounded as well as rubbers is possible concurrently. The infrared absorption spectra of rubbers compounded with several kinds of fillers by this method are described.
\end{abstract}

\section{INTRODUCTION}

In Part I, infrared spectra of various fillers now in use were reported, and absorptions characteristic of them were investigated. The infrared absorption spectra of natural rubbers, synthetic rubbers and other polymers, have already been investigated extensively and utilized in the study of structure or identification of rubbers ${ }^{1 \sim 9}$. The measurement of these rubbers, however, is made on the film method using solvents or pyrolysis, and a direct measurement of vulcanized rubbers compounded with fillers has not yet been conducted. Solely Sheppard and Sutherland ${ }^{102}$ have measured the absorption of rubbers compounded with 27 parts of carbon black, as seen in the report concerning the vulcanization mechanism of natural rubbers, but no outstanding result was achieved. This seems to be due mainly to the difficulty in preparing samples for measuring the infrared absorption spectra of vulcanized rubber compounded with fillers. But, if measurement of infrared absorption spectra is possible with intact vulcanized rubber compounded with fillers themselves, not only the identification of the rubbers used and fillers becomes easy, but also this method will be a powerful means for investigation of the mutual relation between the rubbers and fillers.

\section{SAMPLE RUBBER}

Compounding ratios of the sample used in this experiment are listed in Tables 1 and 2.

\section{PREPARATION OF SAMPLES FOR INFRARED SPECTRA}

The low temperature microtome used was a commercial one (Yamato Köki $K . K$.) which was partly modified. Cooling the sample is made by blowing carbon dioxide gas from a cylinder to sample desk, but since sufficient cooling is often

* 水渡英二, 荒川正文 
Table 1.

\begin{tabular}{lrrrr}
\hline & $\mathrm{A}$ & \multicolumn{1}{c}{$\mathrm{B}$} & \multicolumn{1}{c}{$\mathrm{C}$} & \multicolumn{1}{c}{$\mathrm{D}$} \\
\hline SBR (Plioflex 1502) & 100.0 & 100.0 & 100.0 & 100.0 \\
Zinc oxide & 5.0 & 5.0 & 5.0 & 5.0 \\
Stearic acid & 1.0 & 1.0 & 1.0 & 1.0 \\
Sulfur & 2.0 & 2.0 & 2.0 & 2.0 \\
Promotor DM & 1.5 & 1.5 & 1.5 & 1.5 \\
Promotor M & 0.5 & 0.5 & 0.5 & 0.5 \\
Diethylene glycol & 3.0 & 3.0 & 3.0 & 3.0 \\
Hisil 233 & 50.0 & - & - & - \\
Ultrasil & - & 50.0 & - & - \\
Hakuenka CC & - & - & 50.0 & - \\
Hard clay & - & - & - & 50.0 \\
\hline
\end{tabular}

Vulcanized under pressure $40 \mathrm{lb} / \mathrm{in}^{2}, 20 \mathrm{~min}$.

Table 2.

\begin{tabular}{lrr}
\hline & $\mathrm{E}$ & $\mathrm{F}$ \\
\hline Natural rubber (RSS $\# 1)$ & 100.0 & 100.0 \\
Zinc oxide & 5.0 & 5.0 \\
Stearic acid & 1.0 & 1.0 \\
Sulfur & 3.0 & 3.0 \\
Promotor M & 1.0 & 1.0 \\
Hakuenka CC & 50.0 & - \\
Special Chikyu & - & 50.0 \\
\hline
\end{tabular}

Vulcanized under pressure $40 \mathrm{lb} / \mathrm{in}^{2}, 20 \mathrm{~min}$.

impossible with some samples, a cooling vessel with dry ice-acetone freezing mixture was arranged for preparing section slices. The most favorable temperature for preparing section slices suitable for the measurement of infrared absorption spectra varies with the kind of samples. Namely, when the rubber elasticity is lost and crystallization proceeds no good result was obtained. Good results were obtained at about $-45^{\circ} \mathrm{C}$ for $\mathrm{SBR}$ and at $-55^{\circ} \mathrm{C}$ for natural rubber. The size of samples was $8 \times 10 \mathrm{~mm}$ and had a thickness of $20-30 \mu$. In case of raw rubber, about $1 \mathrm{~g}$ was dissolved in $20 \mathrm{cc}$ benzene, a part of which was spread on a slide glass, benzene was evaporated in a desiccator, and thin films of about $20 \mu$ thickness obtained by stripping from the glass were used in the measurement.

\section{RESULTS}

A Perkin EImer Model-21-spectrometer with $\mathrm{NaCl}$ prism was used in the range between $2-15 \mu$. The results are as follows.

Fig. 1, (a) gives the spectrum of SBR (Plioflex 1502) alone, which coincides well with those often presented up to now. Namely, absorption bands at $1,605 \mathrm{~cm}^{-1}$ and $1,496 \mathrm{~cm}^{-1}$ are attributed to the $\mathrm{C}=\mathrm{C}$ in-plane vibration of the phenyl group ${ }^{122)}$, and these at 759 and $699 \mathrm{~cm}^{-1}$ to the out-plane deformation vibration ${ }^{34)}$. In addition, $994 \mathrm{~cm}^{-1}$ is due to the $\mathrm{CH}$ out of plane vibration of in the vinyl 


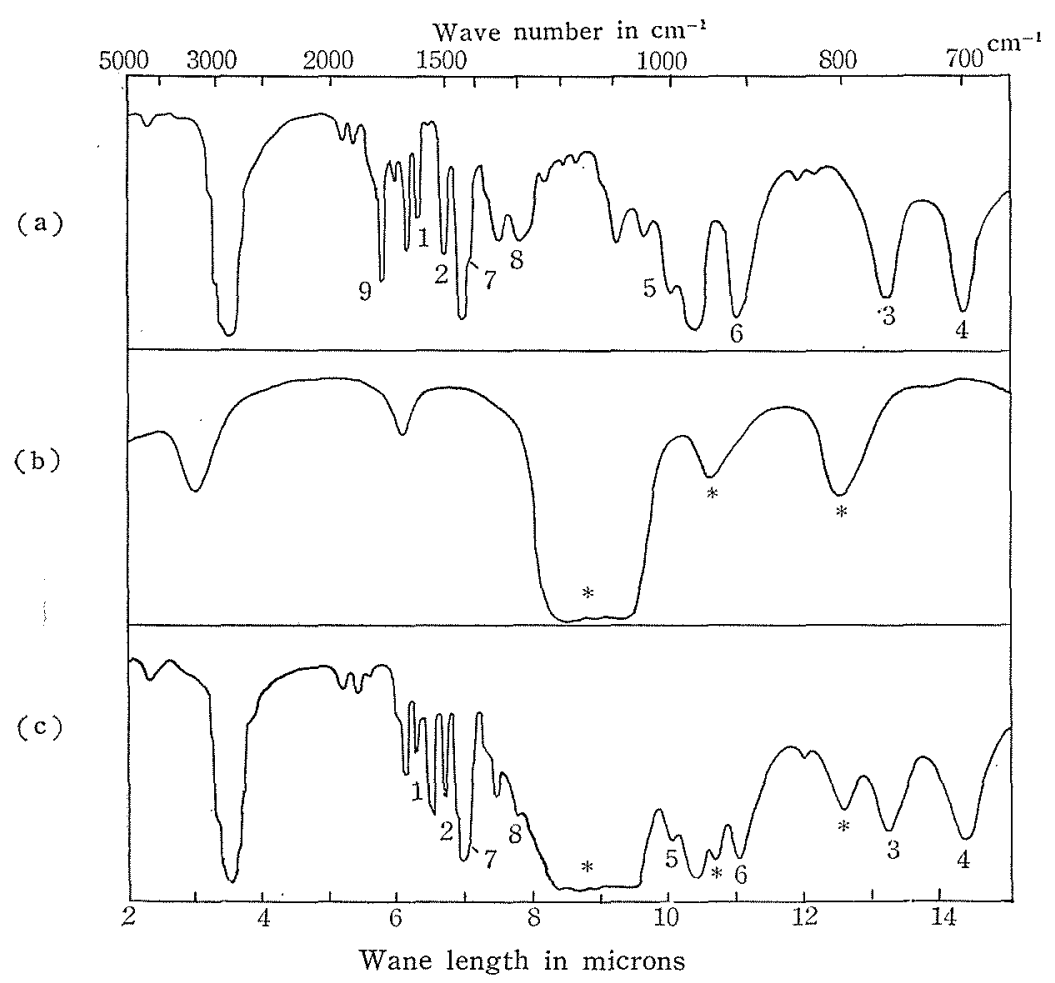

Fig. 1. (a) SBR (Plioflex 1502)

(b) Colloidal silica (Hisil 233)

(c) SBR Compounded with Hisil 233

group ${ }^{5)}, 910 \mathrm{~cm}^{-1}$ similarly to the $\mathrm{CH}_{2}$ out-plane vibration, ${ }^{6)} 1,420 \mathrm{~cm}^{-1}$ to the $\mathrm{CH}_{2}$ in-plane deformation ${ }^{7)}$, and $1,300 \mathrm{~cm}^{-1}$ is due to the $\mathrm{CH}$ in-plane deformation vibration $^{83}$. These absorption bands are all useful for the identification of SBR. 1,710 $\mathrm{cm}^{-1}$ corresponds to the absorption of $>\mathrm{C}=\mathrm{O}^{9}$ and this is considered to be due to the emulsifier contained in the sample, being used during synthesis of SBR.

Fig. 1 (c) gives the infrared absorption spectrum of section of vulcanized rubber, SBR compounded with 50 parts of Hisil 233, which approximately a spectrum obtained by overlapping of spectra of SBR and Hisil. From bands at 1,000 $1,250 \mathrm{~cm}^{-1}, 960 \mathrm{~cm}^{-1}, 810 \mathrm{~cm}^{-1}$, (marked with*, which denotes the absorption due to fillers in the following figure), which are unique bands to colloidal silica described in Part I, together with the absorptions ${ }^{1-8)}$ of SBR mentioned above, it can be learned evidently that this sample came from SBR compounded with colloidal silica prepared by the wet method. Fig. 2 (a) gives SBR compounded with 50 parts of Ultrasil in the same way, and Fig. 2 (b) gives SBR 1772 compounded with 70 parts of Carplex, both of which are also capable of being identified.

Fig. 2 (c) gives SBR compounded with Hakuenka $C C$ and from the bands of carbonate at $1,440-1,550 \mathrm{~cm}^{-1}$ and $875 \mathrm{~cm}^{-1}$ and the bands at 715 and $849 \mathrm{~cm}^{-1}$, it may be found that it is compounded with calcium carbonate of Calcite type. Fig. 2 (d) also gives SBR compounded with 50 parts of Crown Clay, Kaolin Clays have, as described in Part I, bands at $980 \sim 1,100 \mathrm{~cm}^{-1} 910 \mathrm{~cm}^{-1}$ and $785,750,695 \mathrm{~cm}^{-1}$. 
Infrared Studies of Rubber-Filler System. (II)



Fig. 2, SBR compounded with various fillers.
(a) Colloidal silica (Ultrasil)
(b) Colloidal silica (Carplex)
(c) Colloidal calcium carbonate (Hakuenka CC)
(d) Hard clay (Crown clay)

Therefore among the absorption bands of SBR, those at 759 and $699 \mathrm{~cm}^{-1}$ due to the phenyl group and that at $994 \mathrm{~cm}^{-1}$ due to vinyl overlap making the identification difficult, but upon the absorption at $1,605,1,496 \mathrm{~cm}^{-1}$ or $1,420,1,300 \mathrm{~cm}^{-1}$, identification is possible.

Fig. 3 (a) gives the infrared absorption spectra of natural rubber (RSS $: 1$ ), and the unique absorption bands to natural rubbers already presented are as follows.

Characteristic frequency
\[ \begin{array}{c}1,660 \mathrm{~cm}^{-1} \\ 1,450 \mathrm{~cm}^{-1} \\ 1,375 \mathrm{~cm}^{-1}\end{array} \]

$\begin{array}{ll}\text { Type of bond } & \\ \mathrm{C}=\mathrm{C} & 1 \\ -\mathrm{CH}_{3}-\mathrm{CH}_{2} & 2 \\ \mathrm{CH}_{3} & 3\end{array}$


Eiji SUITo and Masafumi ARAKAWA

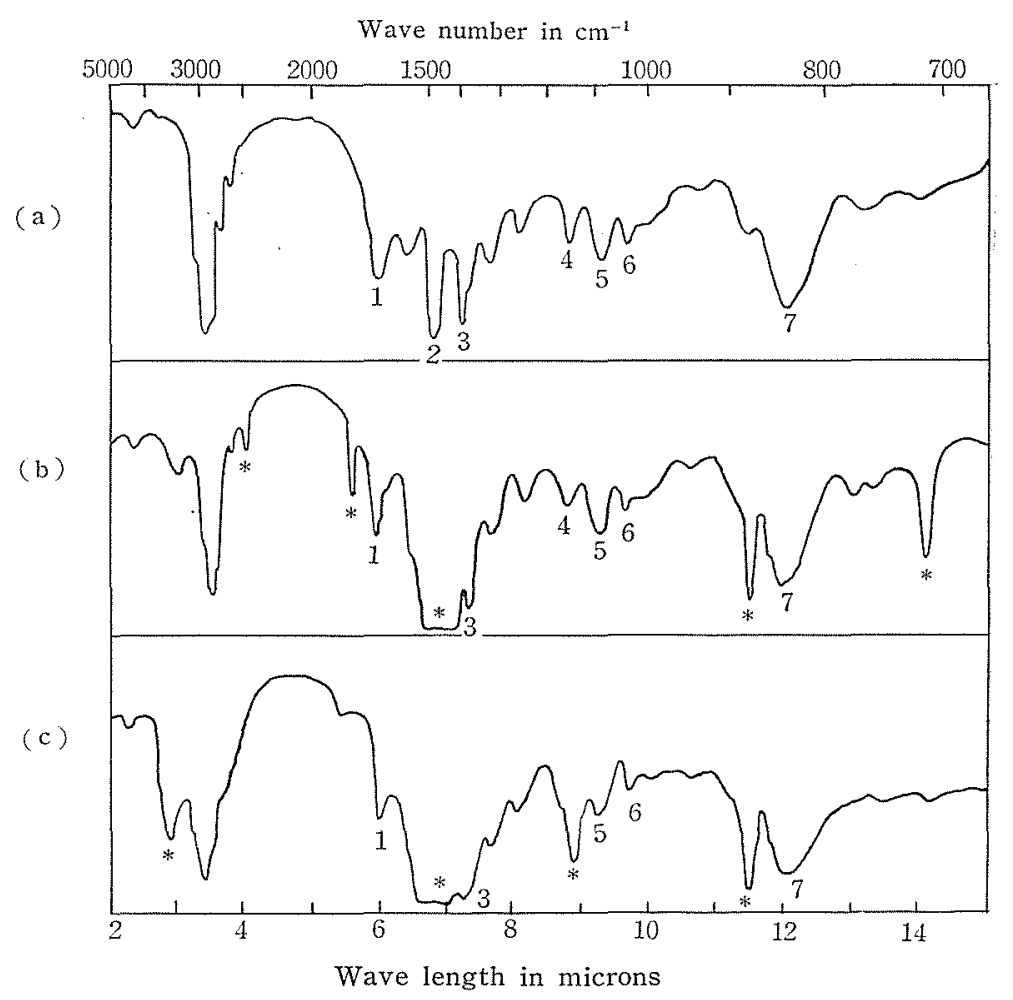

Fig. 3. (a) Natural rubber (RSS 1 ).

(b) RSS 1 compounded with colloidal calcium carbonate (Hakuenka CC).

(c) RSS 1 compounded with basic magnesium carbonate (Special Chikyu).

\begin{tabular}{|c|c|}
\hline $1,130 \mathrm{~cm}^{-1}$ & not yet \\
\hline $1,085 \mathrm{~cm}^{-1}$ & identified \\
\hline $1,040 \mathrm{~cm}^{-1}$ & 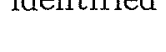 \\
\hline $835 \mathrm{~cm}^{-1}$ & $\begin{array}{l}\mathrm{CH}_{2} \\
-\mathrm{C}=\mathrm{CH}-\end{array}$ \\
\hline
\end{tabular}

Fig, 3 (b) gives the absorption spectra of vulcanized rubber compouded with 100 parts of Hakuenka CC, and Fig. 3 (c) gives that compounded with 50 parts of basic magnesium carbonate, Special Chityu. All of them can be identified from respective characteristic absorptions.

\section{DISCUSSTON}

As seen in the above result, thin section of rubber prepared by a low temperature microtome are suitable for measuring infrared absorption spectra. Sheppared et al. ${ }^{10)}$ inferred that the reason of difficulty in measuring the infrared absorption spectra of rubbers compounded with carbon black lies in the Rayleigh scattering of filler particles, namely, carbon black used by them were particles of a degree of $30 \mathrm{~m} \mu$, and if dispersed uniformly in the rubber, Rayleigh scattering in the infrared region does not occur, but as they exist in aggregations of larger than several $\mu$, scattering takes place, the energy of penetrated light decreases, 
and thus the measurement is made difficult. On the other hand, conversely from this fact, they described that the state of dispersion of filler particles in rubbers is said to be discernible. The state of dispersion of fillers in each sample rubber used in this experiment is inspected ${ }^{11}$ by the replica method or the ultra thin section method using electronmicroscope, and Figs. 1 4, for instance, were obtained indicating that almost good dispersion is attained but at the same time a number of aggregated particles are found to exist in each part. On measurement, however, any phenomena as those by Sheppard et al. was not observed at all. Namely it seems that the reason why they could not obtain good results is not due to the presence of aggregated particles, but due to the strong absorption extending widely in the region of short wave length as seen with carbon black in Fig. 1 of the first report. Accordingly the presumption of dispersed state of filler particles in rubbers by such means cannot be relied on. Moreover, in case of rubber

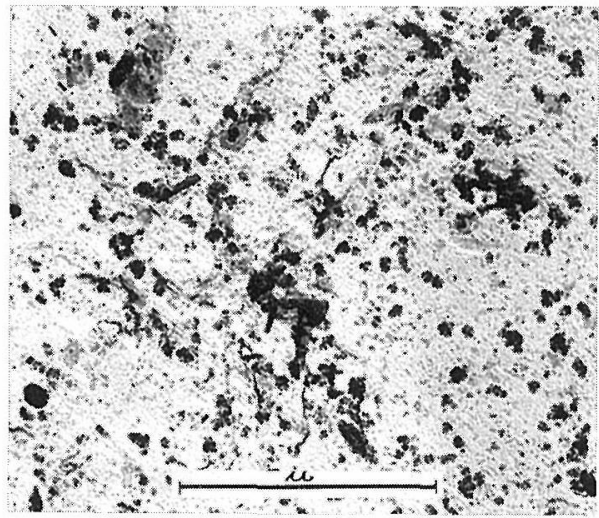

(1)

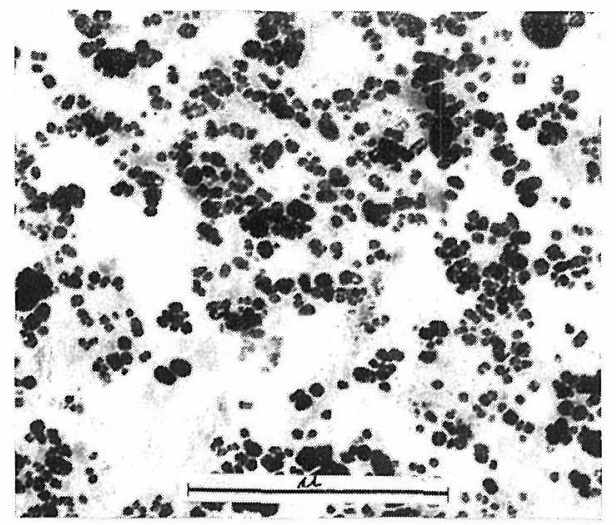

(3)

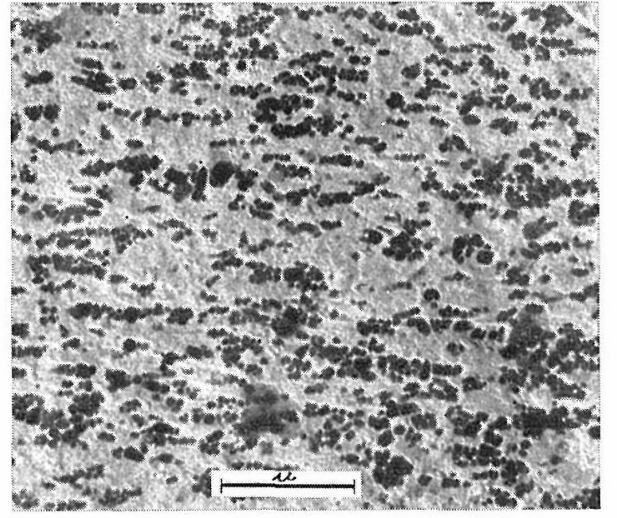

(2)

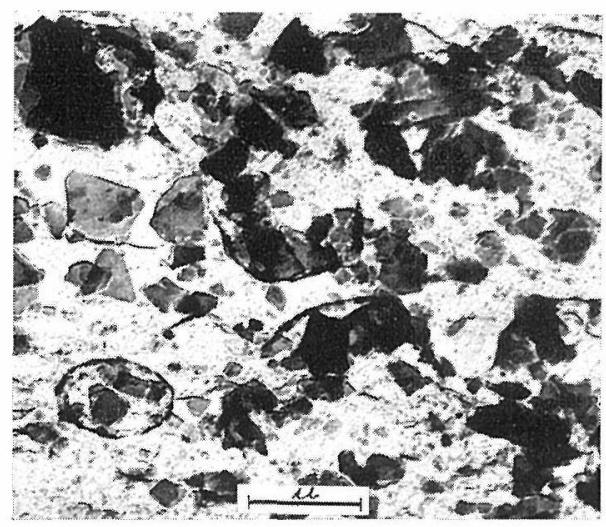

(4)

Fig. 4. Dispersion state of various fillers in the vulcanized rubber.

(1) SBR 1772 compounded with colloidal silica (Carplex). (Replica method)

(2) SBR 1502 compounded with colloidal calcium carbonate (Hakuenka CC). (Replica method)

(3) RSS $¥ 1$ compounded with colloidal calcium carbonate (Hakuenka CC). (Ultra thin section)

(4) RSS $\$ 1$ compounded with basic magnesium carbonate (Special chikyu). (Replica method) 
samples compounded with a large amount of carbon black, the identification by the section method is difficult.

As seen from the absorption spectra measured by this method, the characteristic absorptions in each rubber and filler did not take any change in every sample by the procedure of compounding with fillers and vulcanaization, accompanying entirely no disturbance for the identification of samples. On examination of other absorptions, however, several changes conceivable to be caused by these treatments are observed. The most conspicuous change is that the absorption band at $1,710 \mathrm{~cm}^{-1}$ due to the carboxyl radical disappears in the finished rubber and instead a strong absorption band at $1,540 \mathrm{~cm}^{-1}$ arises. Changes owing to treatments such as compounding with fillers or vulcanization are naturally expected, and consequently there may be a possibility of acquiring some new informations concerning the interaction between fillers and rubbers.

\section{ACKNOWLEGEMENT}

The authors are indebted to both Dr. T. Takenaka and Mr. M. Hayashi for their cooperation in the measurement of infrared absorption spectra and are graterul to Shiraishi Industry Co. for the offer of samples.

\section{REFERENCES}

(1) H. L. Dinsmore and D. C. Smithe., Anal Chem., 20, 11 (1948).

(2) D. L. Harms : Ibid., 25, 1140 (1953).

(3) G. Salomon, C. Van der Schee, J. Polymer Sci., 14, 1.81 (1954).

(4) T. Tanaka, J. Soc. Rubber Ind. Japan, 29, 998 (1956).

(5) S. Kambara and T. Murashima, Ibid., 29, 951 (1956), 30,5, 10 (1957).

(6) T. Tanaka, Kanö and H. Azuma, Ibid., 30, 762 (1957).

(7) G. A. Blokh, A. F. Mal'nev: Rubber Chem Tech., 30, 628 (1957).

(8) D. Hummel, Kautschuk und Gummi, 11, 185 (1958); Rubber Chem. Tech., 32, 854 (1959).

(9) T. Tanaka and H. Azuma, J. Soc. Rubber Ind. Japan, 33, 518 (1960).

(10) N. Sheppard and G.B.B.M. Sutherland, Trans. Faraday Soc., 41, 261 (1945).

(11) E. Suito, M. Arakawa, H. Hasegawa and Y. Furusawa, J. Soc. Rubber Ind. Japan, 26, 453 (1953); 28,540 (1955). 